\title{
ODNOS KREATIVNOSTI SA SHIZOTIPIJOM I PSIHOTICIZMOM KOD STUDENATA UMJETNIČKIH I NEUMJETNIČKIH USMJERENJA
}

\author{
Maša Milas \\ Odjel za psihologiju, Sveučilište u Zadru \\ Obala kralja Petra Krešimira IV br. 2, 23000 Zadar \\ masa.milas94@gmail.com \\ Ana Šimunić \\ Odjel za psihologiju, Sveučilište u Zadru \\ Obala kralja Petra Krešimira IV br. 2, 23000 Zadar \\ asimunic@unizd.hr
}

\begin{abstract}
Sažetak
Proučavanje odnosa kreativnosti i kliničkih te supkliničkih psihopatologija važno je zbog toga što otkriva kognitivne i bihevioralne korelate kreativnosti. Utvrđeno je da su za kreativnost najpogodniji blagi oblici psihopatoloških osobina kao što su shizotipija ili psihoticizam. Cilj istraživanja bio je ispitati odnos kreativnosti i shizotipije te psihoticizma u skupinama studenata umjetničkog i drugih usmjerenja. U istraživanju su sudjelovala 104 studenta umjetničkog i 193 studenta drugih usmjerenja.

Rezultati pokazuju da između dviju skupina studenata postoji statistički značajna razlika u dvjema dimenzijama shizotipije (neobična iskustva i kognitivna dezorganizacija) i u broju kreativnih interesa i aktivnosti. Studenti umjetničkih usmjerenja su izrazili da doživljavaju više neobičnih iskustava poput halucinacija i deluzija te da imaju više dezorganiziranih misli, oslabljenih konceptualnih granica i poteškoća sa zadržavanjem pažnje nego studenti drugih usmjerenja. Također, studenti umjetničkih usmjerenja su naveli veći broj kreativnih interesa $i$ aktivnosti nego studenti drugih usmjerenja. Nadalje, oni studenti koji su iskazali da doživljavaju više neobičnih iskustava i kojima su raspoloženje i ponašanje (posebice vezano uz socijalne norme i konvencije) češće nestabilni, bave se većim brojem kreativnih aktivnosti. S druge strane, oni studenti koji su iskazali veću sklonost introvertiranom, asocijalnom ponašanju sa smanjenom sposobnošću osjećanja ugode, navode manje kreativnih interesa i aktivnosti. Nije utvrđena značajna povezanost psihoticizma i kreativnosti.
\end{abstract}

Ključne riječi: kreativnost, shizotipija, psihoticizam 


\section{UVOD}

Kreativnost podrazumijeva proces produkcije nečeg što je originalno i korisno (Kozbelt, Beghetto i Runco, 2010). Međutim, odavno je prisutna ideja da su kreativne osobe pomalo "lude", odnosno da je kreativan um ujedno i "problematičan". Konkretni primjeri su npr. poznati slikar Van Gogh (bipolarni poremećaj), Mozart (autist), Beethoven (depresija) i brojni drugi. Istraživači su se stoga fokusirali na tzv. tamnu stranu kreativnosti i naglašavaju da je kreativnost zapravo povezana sa sklonošću psihozama, kao što su shizotipija i psihoticizam, a ne i sa samim psihičkim bolestima (Acar i Sen, 2013; Kyaga i sur., 2013).

Shizotipija podrazumijeva prisutnost obrazaca mišljenja i/ili sustava vjerovanja sličnih shizofreničnim, uključujući karakteristike poput magičnog mišljenja, neobičnih perceptivnih iskustava i paranormalnih vjerovanja (American Psychiatric Association, 2013). Najopsežnija mjera shizotipalnih crta ličnosti je "O-LIFE" inventar osjećaja i ponašanja (Oxford-Liverpool Inventory for Feelings and Experiences: Mason, Claridge i Jackson, 1995). Sastoji se od dimenzije pozitivne shizotipije nazvane Neobična iskustva koja je slična pozitivnim simptomima shizofrenije poput halucinacija i deluzija, uključuje magično mišljenje, paranoju, sumnjičavost, perceptivno iskrivljavanje i doživljavanje maničnih stanja. Druga dimenzija, Introvertivna anhedonija, podrazumijeva sklonost introvertiranom, asocijalnom ponašanju sa smanjenom sposobnošću osjećanja ugode zbog socijalnih interakcija i drugih aktivnosti koje većina doživljava ugodnima. Treću dimenziju, poznatu kao Kognitivna dezorganizacija, karakteriziraju dezorganizirane misli, oslabljene konceptualne granice, poteškoće sa zadržavanjem pažnje, socijalna inhibiranost i neuroticizam (Batey i Furnham, 2008). Četvrta dimenzija, Impulzivni nekonformizam, odnosi se na nestabilno raspoloženje i ponašanje, posebice vezano uz socijalne norme i konvencije. Utvrđeno je da zdravi pojedinci visokih razina shizotipalnih crta pokazuju izraženo divergentno mišljenje, odnosno sposobnost generiranja novih asocijacija i ideja koja proizlazi iz fleksibilnog, otvorenog razmišljanja u "više smjerova" (Green i Williams, 1999). Nelson i Rawlings (2010) su u svom istraživanju utvrdili da je skupina umjetnika postizala više rezultate od normativnih na mjeri pozitivne shizotipije (neobična iskustva) i to se ujedno pokazalo kao najbolji prediktor rezultata na skali kreativnih iskustava. Nekoliko je istraživanja pokazalo da su samo dimenzije neobična iskustva i impulzivni nekonformizam (ali ne i kognitivna dezorganizacija) značajno povezane s kreativnošću (npr. Fisher i sur., 2004). Postoji nekoliko mogućih poveznica kreativnosti i shizotipije. Za kognitivni stil kreativnih osoba smatra se da je preopširan (Eysenck, 1993, prema Batey i Furnham, 2008), što podrazumijeva nemogućnost održavanja konceptualnih granica koje karakteriziraju "normalno" mišljenje. S neurofiziološkog aspekta, utvrđeno je da osobe koje imaju visoke razine shizotipalnih crta pokazuju reduciranu hemisfernu asimetriju (Suzuki i Usher, 2009), što olakšava pronalaženje veze između naizgled nespojivih koncepata i pogoduje kreativnom mišljenju (Lindell, 2011). 
Psihoticizam, dimenzija ličnosti koju karakterizira hladno, agresivno i impulzivno ponašanje te nedostatak empatije (Eysenck, 1995), pokazala se povezanom s raznim facetama kreativnosti, a naročito s originalnošću (Fink, Slamar-Halbedl, Unterrainer i Weiss, 2012). Eysenck je psihoticizam predstavio kao kontinuum na čijem se jednom kraju nalaze osobine poput altruističnosti, empatije, sklonosti konformiranju, dok suprotan kraj karakteriziraju osobine poput impulzivnosti, agresije ili hostilnosti, što je povezano sa sklonosti nekonformizmu. To može dijelom objasniti vezu originalnosti i psihoticizma. Rawlings, Twomey, Burns i Morris (1998) su utvrdili vezu između psihoticizma, otvorenosti $\mathrm{k}$ iskustvu, traženju senzacija $\mathrm{i}$ kreativnosti.

Cilj je bio ispitati odnos između samoprocijenjene kreativnosti i shizotipije te psihoticizma u skupinama studenata umjetničkog i drugih usmjerenja. Ispitana je razlika u mjerama kreativnosti i dimenzijama shizotipije te psihoticizma s obzirom na vrstu studijskog usmjerenja. Očekivalo se da će skupina umjetničkog studijskog usmjerenja imati više rezultate na svim spomenutim mjerama, osim na dimenziji Introvertivna anhedonija. Nadalje, ispitana je povezanost kreativnih interesa i aktivnosti s različitim dimenzijama shizotipije i psihoticizmom. Pretpostavilo se da će kreativniji pojedinci izražavati više neobičnih iskustava impulzivnog nekonformizma. S obzirom na opširan kognitivni stil kreativnih osoba pretpostavilo se da će kreativniji pojedinci imati veći stupanj kognitivne dezorganizacije te da će iskazivati manju razinu introvertivne anhedonije. $\mathrm{Na}$ koncu, pretpostavila se niska pozitivna povezanost kreativnosti i psihoticizma.

\section{METODA}

\section{Sudionici}

U ispitivanju su sudjelovala 104 studenta umjetničkog i 193 neumjetničkih usmjerenja. U ukupnom uzorku je bilo 66 muškaraca i 231 žena, a raspon dobi se kretao od 18 do $36(M=21,64, S D=2,29)$.

\section{Instrumenti}

Upitnik općih podataka koji je sadržavao pitanja o spolu, dobi i studijskom usmjerenju.

Skraćena verzija "O-LIFE" upitnika (Oxford-Liverpool Inventory of Feelings and Experiences short version, sO-LIFE; Mason, Linney i Claridge, 2005) koja je prevedena s engleskog na hrvatski jezik. Mjeri četiri dimenzije shizotipije: neobična iskustva (12 čestica; npr. "Kada ste u mraku, vidite li često oblike i forme kojih za- 
pravo nema?"), introvertivnu anhedoniju (10 čestica; npr. "Postoji li vrlo mali broj aktivnosti u kojima ste stvarno uživali?"), kognitivnu dezorganizaciju (11 čestica; “Ometa li Vas sanjarenje lako u poslu?") i impulzivni nekonformizam (10 čestica; npr. "Biste li voljeli da Vas se drugi ljudi boje?"). Ispitanici na svaku česticu odgovaraju s "da" ili "ne", pri čemu se odgovor boduje s 1 ako implicira veću razinu ispitane dimenzije odnosno s 0 ako ne. Veći rezultat upućuje na veću izraženost osobina karakterističnih za tu dimenziju.

Prvo je provjerena pretpostavljena četverofaktorska struktura upitnika. Provedena je konfirmatorna faktorska analiza korištenjem programa MPlus 6.0 (Muthen i Muthen, 2014) uz primjenu $W L S M V$ metode prilikom procjene parametara u modelu zbog kategoričke prirode podataka. Pri procjeni modela, na faktoru impulzivni nekonformizam bila su samo dva značajna zasićenja i stoga se, kao i kod nekih prijašnjih istraživanja (npr. Fonseca-Pedrero, Ortuno-Sierra, Mason i Muniz, 2015) nije pokazao kao valjan faktor te nije dalje analiziran. Nakon ovog je procijenjen model s ostala tri pretpostavljena faktora. Vrijednosti indeksa za procjenu prikladnosti opisanog modela uputili su na prihvatljivo slaganje modela s podacima ( $\mathrm{Hu} \mathrm{i}$ Bentler, 1999). Zasićenje jedne čestice faktorom Introvertivna anhedonija nije bilo značajno, pa je u ponovljenoj procjeni modela izbačena. Uvidom u predložene modifikacijske indekse odlučeno je da se u model uvedu parametri koji se odnose na korelacije reziduala nekoliko čestica za koje je moguće da dijele određeni dio varijance koji nije obuhvaćen latentnim faktorima zbog sadržaja koji je povezan s potencijalnim nezgodama (nesreće, ometanje posla, napučena soba). Nakon uvođenja ovih parametara, nije više bilo predloženih modifikacijskih indeksa, a vrijednosti indeksa slaganja bile su sljedeće: $\chi^{2}=497,84 ; \mathrm{df}=458 ; p=0,010\left(\chi^{2} / \mathrm{df}=1,09\right)$; $W R M R=0,913 ; R M S E A=0,017 ; C F I=0,967 ; T L I=0,964$, uputivši na poboljšano slaganje modela. Dobivene pouzdanosti (Cronbach alpha) ovako formiranih subskala na ovom uzorku su sljedeće: Introvertivna anhedonija 0,64; Neobična iskustva 0,68 ; Kognitivna dezorganizacija 0,72 .

Kratki inventar simptoma (engl. Brief Symptom Inventory, BSI; Derogatis, 1993; Štribić, 2005) - inventar samoiskaza za procjenu simptoma psihopatologije i psihološke nelagode psihijatrijskih i ostalih pacijenata, kao i zdravih odraslih osoba i adolescenata. Svakoj čestici BSI je pridružena ljestvica za procjenu razine nelagode sa pet stupnjeva u rasponu od 0 (nimalo) do 4 (vrlo mnogo). Veći rezultat upućuje na veću izraženost određenog simptoma. Za potrebe ovog istraživanja korištena je dimenzija psihoticizma, kao kontinuirana dimenzija koja se odnosi na povučen, izoliran i shizoidan način života, a može odražavati postupan prijelaz od blage interpersonalne otuđenosti do manifestne psihoze. Konkretno, inventar počinje pitanjem "Koliko su Vas mučili sljedeći problemi?", a primjer navedenih problema za Psihoticizam je: "Pomisao da netko kontrolira Vaše misli". Inventar ima zadovoljavajuću pouzdanost s koeficijentom unutarnje konzistencije $\alpha=0,87$. 
Check lista kreativnih interesa i aktivnosti (Griffin i McDermott, 1998) sastoji se od dva dijela; prvi mjeri broj trenutačnih kreativnih interesa osobe, a drugi broj kreativnih aktivnosti kojima se osoba bavila posljednjih godinu dana. Obje liste se sastoje od 26 čestica koje su podijeljene u četiri potkategorije: vizualne umjetnosti (npr. fotografija), izvedbena umjetnost (npr. drama), s fokusom na riječi (npr. poezija) ili glazbu te kreativnost u domeni domaćinstva (npr. šivanje odjeće). Konačni rezultat se formira tako da se zbroji ukupan broj 1) interesa i 2) aktivnosti koje je svaki ispitanik naveo.

\section{Postupak}

Ispitivanje je provedeno u periodu od siječnja do ožujka 2016. godine. Mjerni instrument je bio prezentiran u obliku online upitnika i dijeljen je uz pomoć osoba koje studiraju na akademijama i ostalim fakultetima umjetničkog usmjerenja među njihovim kolegama kako bi se skupio približno jednak broj ispitanika u oba uzorka.

\section{REZULTATI}

Ako uzmemo u obzir kriterije prema kojima vrijednosti spljoštenosti i (a)simetričnosti u rasponu od -2 do +2 upućuju na normalnu distribuciju podataka, može se reći da su dobivene vrijednosti istih u granicama prihvatljivog, te da se mogu koristiti parametrijski statistički postupci (Kline, 2011). Nadalje, provjerene su i homogenosti varijanci. S obzirom na to da je i taj preduvjet bio zadovoljen, izračunati su t-testovi. Utvrđena je statistički značajna razlika u dvije dimenzije shizotipije

Tablica 1 Deskriptivni parametri i rezultati t-testova za ispitivanje razlika u broju kreativnih interesa i aktivnosti, psihoticizmu te tri dimenzije shizotipije između skupina studenata umjetničkog i drugih usmjerenja

\begin{tabular}{|c|c|c|c|c|c|c|c|}
\hline \multirow[b]{2}{*}{ Varijable } & \multicolumn{2}{|c|}{$\begin{array}{l}\text { Umjetničko } \\
\text { usmjerenje } \\
(N=104)\end{array}$} & \multicolumn{2}{|c|}{$\begin{array}{c}\text { Neumjetničko } \\
\text { usmjerenje } \\
(N=193)\end{array}$} & \multirow[b]{2}{*}{$t$} & \multirow[b]{2}{*}{$d f$} & \multirow[b]{2}{*}{$p$} \\
\hline & $M$ & $S D$ & $M$ & $S D$ & & & \\
\hline Neobična iskustva & 6,73 & 2,59 & 5,78 & 2,61 & $-3,01$ & 295 & 0,003 \\
\hline Kognitivna dezorganizacija & 6,51 & 2,71 & 5,76 & 2,74 & $-2,27$ & 295 & 0,024 \\
\hline Introvertivna anhedonija & 2,13 & 1,77 & 2,27 & 1,99 & 0,64 & 295 & 0,522 \\
\hline Psihoticizam & 1,14 & 0,85 & 0,97 & 0,88 & $-1,57$ & 295 & 0,118 \\
\hline Kreativne aktivnosti & 6,78 & 3,22 & 4,09 & 3,01 & $-5,06$ & 295 & 0,000 \\
\hline Kreativni interesi & 11,86 & 5,21 & 8,65 & 5,19 & $-7,17$ & 295 & 0,000 \\
\hline
\end{tabular}


Tablica 2 Rezultati analiza kovarijance za ispitivanje razlika u psihoticizmu i tri dimenzije shizotipije između skupina studenata umjetničkog i drugih usmjerenja, s kreativnim interesima $\mathrm{i}$ aktivnostima kao kovarijatama

\begin{tabular}{lccc}
\hline Varijable & $F$ & $d f$ & $p$ \\
\hline Neobična iskustva & 4,33 & $\mathbf{2 9 3}$ & $\mathbf{0 , 0 3 8}$ \\
kovarijata: Kreativni interesi & 0,39 & & 0,533 \\
kovarijata: Kreativne aktivnosti & $\mathbf{3 , 9 3}$ & & 0,048 \\
Kognitivna dezorganizacij & $\mathbf{8 , 7 9}$ & $\mathbf{2 9 3}$ & $\mathbf{0 , 0 0 3}$ \\
kovarijata: Kreativni interesi & 0,63 & & 0,428 \\
kovarijata: Kreativne aktivnosti & $\mathbf{6 , 0 2}$ & & 0,015 \\
Introvertivna anhedonija & 0,64 & 293 & 0,423 \\
kovarijata: Kreativni interesi & 3,26 & & 0,072 \\
kovarijata: Kreativne aktivnosti & 3,26 & & 0,072 \\
Psihoticizam & 3,81 & 293 & 0,052 \\
kovarijata: Kreativni interesi & 0,15 & & 0,702 \\
kovarijata: Kreativne aktivnosti & 0,71 & & 0,401 \\
\hline
\end{tabular}

(Tablica 1): studenti umjetničkog usmjerenja iskazali su značajno više karakteristika vezanih za dimenzije Neobična iskustva i Kognitivna dezorganizacija. Razlike su potvrđene i analizama kovarijance uz kreativne interese/aktivnosti kao kovarijate (Tablica 2). Također se pokazalo da je skupina studenata umjetničkog usmjerenja imala veći broj kreativnih aktivnosti i interesa. Na ostalim mjerama nisu utvrđene značajne razlike između skupina.

Provjerom odnosa između kreativnosti i različitih dimenzija shizotipije utvrđeno je da osobe koje se bave većim brojem kreativnih aktivnosti, ujedno i doživljavaju više neobičnih iskustava (Tablica 3). Osobe koje se bave većim brojem kreativnih

Tablica 3 Pearsonovi koeficijenti korelacije između kreativnosti i različitih dimenzija shizotipije, te psihoticizma $(N=295)$

\begin{tabular}{lccccc}
\hline Varijable & $\begin{array}{c}\text { Kreativni } \\
\text { interesi }\end{array}$ & $\begin{array}{c}\text { Kreativne } \\
\text { aktivnosti }\end{array}$ & NI & KD & IA \\
\hline Neobična iskustva (NI) & 0,08 & $0,17^{*}$ & & & \\
$\begin{array}{l}\text { Kognitivna } \\
\text { dezorganizacija (KD) }\end{array}$ & 0,00 & $-0,08$ & $0,37^{* *}$ & & \\
$\begin{array}{l}\text { Introvertivna } \\
\text { anhedonija (IA) }\end{array}$ & $-0,13^{*}$ & $-0,13^{*}$ & 0,10 & $0,35^{* *}$ & \\
Psihoticizam & $-0,03$ & $-0,03$ & $0,42^{* *}$ & $0,45^{* *}$ & $0,39^{* *}$ \\
\hline
\end{tabular}

${ }^{*} p<0,05 ; * * p<0,01$ 
Tablica 4 Rezultati regresijskih analiza s 1) kreativnim interesima i 2) kreativnim aktivnostima kao kriterijima, a dimenzijama shizotipije i psihoticizmom kao prediktorima, uz kontrolu studijskog usmjerenja (0-neumjetničko; 1-umjetničko) $(N=295)$

\begin{tabular}{|c|c|c|c|c|}
\hline \multirow{2}{*}{$\begin{array}{l}\text { Kriterij } \\
\text { Prediktori }\end{array}$} & \multicolumn{2}{|c|}{ Kreativni interesi } & \multicolumn{2}{|c|}{ Kreativne aktivnosti } \\
\hline & Korak 1 & Korak 2 & Korak 1 & Korak 2 \\
\hline Studijsko usmjerenje & $\begin{array}{l}\underline{\beta=0,26^{* *}} \\
R=0,27^{* *} \\
R^{2}=0,07\end{array}$ & $\beta=0,24 * *$ & $\begin{array}{l}\frac{\beta=0,35^{* *}}{R=0,37^{* *}} \\
R^{2}=0,13\end{array}$ & $\beta=0,34 * *$ \\
\hline Neobična iskustva & & $\beta=0,05$ & & $\beta=0,16^{* *}$ \\
\hline Kognitivna dezorganizacija & & $\beta=0,02$ & & $\beta=-0,11$ \\
\hline Introvertivna anhedonija & & $\beta=-0,17 * *$ & & $\beta=-0,13^{*}$ \\
\hline Psihoticizam & & $\begin{array}{l}\beta=-0,01 \\
R=0,32 * * \\
R^{2}=0,11 \\
\Delta R^{2}=0,032 *\end{array}$ & & $\begin{array}{l}\beta=-0,02 \\
R=0,44^{* *} \\
R^{2}=0,19 \\
\Delta \mathrm{R}^{2}=0,055^{* *}\end{array}$ \\
\hline
\end{tabular}

${ }^{*} p<0,05 ; * * p<0,01$

aktivnosti i koje imaju više kreativnih interesa iskazuju manje karakteristika Introvertivne anhedonije. Nije utvrđena značajna povezanost psihoticizma i kreativnih interesa i aktivnosti. Navedeni odnosi (prediktivne vrijednosti) potvrđeni su i regresijskim analizama uz kontrolu studijskog usmjerenja (Tablica 4).

\section{RASPRAVA}

Proučavanje odnosa supkliničkih razina psihopatologije i kreativnosti korisno je iz nekoliko razloga. Jedan od razloga koji se može istaknuti odnosi se na činjenicu da se tako otkrivaju kognitivni i bihevioralni korelati kreativnosti, konstrukta koji je vrlo kompleksan i još uvijek nedovoljno istražen, pa je cilj ovog istraživanja bio provjeriti odnos kreativnosti i shizotipije te psihoticizma u skupinama studenata umjetničkog i drugih usmjerenja.

Očekivanja vezana za razlike između studenata umjetničkih i neumjetničkih usmjerenja su potvrđena, osim kad se radilo o psihoticizmu, što je sukladno rezultatima koje su dobili O’Reilly, Dunbar i Bentall (2001). Objašnjenje se krije u karakteristikama kognitivnog stila zajedničkim za kreativno i psihotično mišljenje, gdje spadaju reducirana latentna inhibicija koja može objasniti vezu doživljavanja neobičnih iskustava i kognitivne dezorganizacije s kreativnosti (Fink i sur., 2014). Značajna razlika među dvije skupine ispitanika nije utvrđena u dimenziji introvertivna anhedonija, što je bilo očekivano, te su imali podjednak vrlo nizak rezultat na toj dimenziji $\left(M_{u}=2,13\right.$ i $M_{n}=2,27$ od maksimalno mogućeg rezultata koji iznosi 9). Obje su skupine studenata u usporedbi s uzorcima u prijašnjim istraživanjima 
(Štribić, 2005) u prosjeku imale veće rezultate na mjeri psihoticizma. Razlog tome može biti činjenica da se radi o mlađim osobama koje u današnjim ekonomskim prilikama manifestiraju strah, srdžbu i/ili zabrinutost za vlastitu ili sigurnost bližnjih (pri čemu mogu biti izraženi hostilnost i fobičnost), a ove osobine mogu biti povezane s psihoticizmom (Štribić, 2005). Na koncu, nije iznenađujuće da se studenti umjetničkog usmjerenja bave većim brojem kreativnih aktivnosti i da su općenito skloniji kreativnim interesima.

Utvrđena je pretpostavljena pozitivna povezanost dimenzije neobična iskustva $\mathrm{i}$ kreativnosti. Pozitivna povezanost neobičnih iskustava i samoprocijenjene kreativnosti može se objasniti reduciranom latentnom inhibicijom koja facilitira perceptivno iskrivljavanje i omogućava lakši pristup nesvjesno procesiranim informacijama (Barrantes-Vidal, 2014). Tome pripomaže i preopširno mišljenje. Nadalje, utvrđeno je da, što je osoba više na dimenziji introvertivne anhedonije, sudjeluje u manjem broju kreativnih aktivnosti. S obzirom na to da pojedinci koji iskazuju doživljavanje više karakteristika introvertivne anhedonije ne uživaju u aktivnostima u kojima uživa većina drugih, moguće je da ih ne privlače ni kreativne aktivnosti.

Nije utvrđena značajna povezanost kognitivne dezorganizacije i broja kreativnih interesa i aktivnosti, premda je utvrđena značajna razlika među skupinama studenata. Moguće je da, iako oslabljene konceptualne granice pogoduju kreativnom mišljenju, socijalnoj inhibiranosti i problemima s pažnjom (Batey i Furnham, 2008), i takve granice otežavaju manifestiranje te kreativnosti u određenim aktivnostima i interesima. Dakle, veza shizotipije i kreativnosti nije uniformna te samo određene dimenzije shizotipije pogoduju kreativnosti, dok druge mogu biti kontraproduktivne. Shizofreni spektar pokazuje odnos "obrnutog-U” s kreativnošću.

Očekivala se niska pozitivna povezanost kreativnosti i psihoticizma, ali povezanost nije dobivena. Razlog može biti u korištenju različitih mjera kreativnosti i psihoticizma. Npr. u istraživanju Finka i sur. (2012) u kojem je utvrđen pretpostavljeni odnos, psihoticizam je mjeren Eysenckovim upitnikom ličnosti (EPQ), fokus je bio na dimenziji originalnosti, a kreativnost je bila operacionalizirana kao broj kreativnih interesa i aktivnosti.

S obzirom na brojne načine definiranja kreativnosti mogućnosti za ispitivanje veze s kliničkim i supkliničkim razinama psihopatologije su uistinu raznolike. Ipak, postoje određeni nedostaci ovog istraživanja. Uzorak bi bilo poželjno izjednačiti po mjestu studiranja i po spolu kako bi se barem donekle mogli kontrolirati utjecaji stila življenja u različitim gradovima. Naime, dodatnom analizom rezultata ovog istraživanja utvrđeno je značajno više kreativnih aktivnosti kod ispitanika iz Zagreba, u usporedbi s onima iz Splita i Zadra, pa je vjerojatno da je okolina u Zagrebu poticajnija i sadržajnija od Splita i Zadra kad se radi o mogućnostima bavljenja kreativnim aktivnostima. Glavni nedostatak mjernih instrumenata je što se radilo o samoiskazima, što čini upitnom objektivnost podataka. Uz to, trebalo bi napraviti validaciju mjere dimenzija shizotipije na reprezentativnijem uzorku, a vjerojatno i razviti pogodnije, pouzdanije/valjanije mjere tih dimenzija, posebice kad se radi 
o impulzivnom nekonformizmu. U budućim istraživanjima na hrvatskom populacijskom uzorku moglo bi se usporediti više različitih mjera kreativnosti u njihovu odnosu s dimenzijama shizotipije i psihoticizmom. Isto tako, istraživanja pokazuju da odnos psihoticizma s kreativnošću varira s obzirom na korišteni instrument (Acar i Runco, 2012) pa bi bilo poželjno uključiti više različitih mjera i za tu dimenziju ličnosti.

\section{LITERATURA}

Acar, S. i Runco, M. A. (2012). Psychoticism and creativity: A meta-analytic review. Psychology of Aesthetics, Creativity, and the Arts, 6(4), 341-350.

Acar, S. i Sen, S. (2013). A multilevel meta-analysis of the relationship between creativity and schizotypy. Psychology of Aesthetics, Creativity, and the Arts, 7(3), 214-228.

American Psychiatric Association. (2013). Diagnostic and Statistical Manual of Mental Disorders, 5th Ed. Arlington, VA: American Psychiatric Publishing.

Barrantes-Vidal, N. (2014). Creativity and the spectrum of affective and schizophrenic psychoses. Creativity and mental illness, 169-204.

Batey, M. i Furnham, A. (2008). The relationship between measures of creativity and schizotypy. Personality and Individual Differences, 45 (8), 816-821.

Derogatis, L.R. (1993). BSI Brief Symptom Inventory: Administration, Scoring, and Procedure Manual (4th Ed.). Minneapolis, MN: National Computer Systems

Eysenck, H. J. (1995). Creativity as a product of intelligence and personality. In International handbook of personality and intelligence (pp. 231-247). Springer US.

Fink, A., Slamar-Halbedl, M., Unterrainer, H. F. i Weiss, E. (2012). Creativity: genius, madness, or a combination of both? Psychology of Aesthetics, creativity, and the arts, 6 , 11-18.

Fink, A., Weber, B., Koschutnig, K., Benedek, M., Reishofer, G., Ebner, F., ... i Weiss, E. M. (2014). Creativity and schizotypy from the neuroscience perspective. Cognitive, Affective, \& Behavioral Neuroscience, 14(1), 378-387.

Fisher, J. E., Mohanty, A., Herrington, J. D., Koven, N. S., Miller, G. A. i Heller, W. (2004). Neuropsychological evidence for dimensional schizotypy: Implications for creativity and psychopathology. Journal of Research in Personality, 38(1), 24-31.

Fonseca-Pedrero, E., Ortuño-Sierra, J., Mason, O. J., \& Muñiz, J. (2015). The Oxford-Liverpool Inventory of Feelings and Experiences short version: Further validation. Personality and Individual Differences, 86, 338-343.

Green, M. J. i Williams, L. M. (1999). Schizotypy and creativity as effects of reduced cognitive inhibition. Personality and Individual Differences, 27, 263-276.

Griffin, M. i McDermott, M. (1998). Exploring a tripartite relationship between rebelliousness, openness to experience and creativity. Social Behavior and Personality An International Journal, 26(4):347-356.

Hu, L., Bentler, P.M. (1999). Cutoff criteria for fit indexes in covariance structure analysis: Conventional criteria versus new alternatives. Structural Equation Modelling, 6, 1-55. 
Kline, R.B. (2011). Principles and practice of structural equation modelling, $3^{\text {rd }}$ ed. New York: The Guilford Press.

Kozbelt, A., Beghetto, R. A. i Runco, M. A. (2010). Theories of creativity. The Cambridge handbook of creativity, 20-47. New York: Cambridge University Press.

Kyaga, S., Landén, M., Boman, M., Hultman, C. M., Långström, N. i Lichtenstein, P. (2013). Mental illness, suicide and creativity: 40-year prospective total population study. Journal of psychiatric research, 47(1), 83-90.

Lindell, A. K. (2011). Lateral thinkers are not so laterally minded: Hemispheric asymmetry, interaction, and creativity. Laterality: Asymmetries of Body, Brain and Cognition, 16(4), 479-498.

Mason, O., Claridge, G. i Jackson, M. (1995). New scales for the assessment of schizotypy. Personality and Individual Differences, 18, 7-13.

Mason, O., Linney, Y. i Claridge, G. (2005). Short scales for measuring schizotypy. Schizophrenia Research, 78(2), 293-296.

Muthen, L.K. i Muthen, B.O. (2014). MPlus User's Guide. Seventh Edition. Los Angeles, CA: Muthen \& Muthen.

Nelson, B. i Rawlings, D. (2010). Relating schizotypy and personality to the phenomenology of creativity. Schizophrenia Bulletin, 36(2), 388-399.

O'Reilly, T., Dunbar, R. i Bentall, R. (2001). Schizotypy and creativity: an evolutionary connection? Personality and Individual Differences, 31(7), 1067-1078.

Rawlings, D., Twomey, F., Burns, E. i Morris, S. (1998) Personality, creativity and aesthetic preference. Comparing psychoticism, sensation seeking, schizotypy and openess to experience. Empirical studies of arts, 16, 153-178.

Suzuki, A. i Usher, M. (2009). Individual differences in language lateralisation, schizotypy and the remote-associate task. Personality and Individual Differences, 46(5), 622-626.

Štribić, M. (2005). Psihometrijska validacija Derogatisovog kratkog inventara simptoma (BSI). Neobjavljeni diplomski rad. Zagreb: Odsjek za psihologiju Filozofskog fakulteta u Zagrebu.

\title{
THE RELATIONSHIP OF CREATIVITY WITH SCHIZOTYPY AND PSYCHOTICISM IN STUDENTS OF ARTISTIC AND OTHER DOMAINS
}

\begin{abstract}
The study of the relationships between creativity and clinical and sub-clinical psychopathologies is important, because it provides insight into the cognitive and behavioural correlates of creativity. It is found that milder forms of psychopathological traits, such as schizotypy or psychoticism, may be the most beneficial to creativity.
\end{abstract}


Considering this fact, the aim of this study was to examine the relationship between creativity, schizotypy, and psychoticism in groups of students of artistic and other domains. The study included 104 artistic domain students and 193 nonartistic domain students.

The results show a statistically significant difference in two schizotypy dimensions (unusual experiences and cognitive disorganisation) and in the number of creative interests and activities between the two groups of students. Students from artistic colleges experience more unusual experiences such as hallucinations and delusions and have more disorganised thoughts, looser conceptual boundaries and attention deficits compared to nonartistic domain students. Also, artistic domain students reported a greater number of creative interests and activities than nonartistic domain students. Furthermore, students who have more unusual experiences and whose mood and behaviour (especially one connected with social norms and conventions) are unstable more often, have more creative activities. On the other hand, those students who are more prone to introverted, asocial behaviour with reduced ability in experiencing pleasure, have less creative interests and activities. No significant correlation was found between psychoticism and creativity.

Key words: creativity, schizotypy, psychoticism 
